\title{
Effects of Extensive Reading on Learners: How It Develops Certain Points in Vocabulary and Sentence Structure
}

\author{
Bünyamin Celik ${ }^{1}$ \\ ${ }^{1}$ Department of Languages, Ishik University, Erbil, Iraq \\ Correspondence: Bünyamin Celik, Department of Languages, Ishik University, Erbil, Iraq. E-mail: \\ bunyamin.celik@ishik.edu.iq
}

Received: September 27, 2017 Accepted: October 20, 2017 Online Published: December 23, 2017

doi:10.5539/ijel.v8n2p73

URL: http://doi.org/10.5539/ijel.v8n2p73

\begin{abstract}
This study will handle extensive reading and its impacts on foreign language learning. There is much research on it and how it differs from intensive reading. This study reviewed the related literature and looked into adult learners of English in elementary and pre-intermediate level. Certain types of vocabulary was picked from a story and the participants' knowledge was tested before and after reading in order to check and note down the changes that extensive reading provided. Moreover, their knowledge about sentence structure was also examined and the change of attitude was inserted in the study. Although extensive reading has nothing or very little with pronunciation, some important points were illuminated in the study.
\end{abstract}

Keywords: extensive reading, intensive reading, adult learners, collocations, pronunciation

\section{Introduction}

Reading in a foreign language has an important impact on learning, and it was classified into different forms according to how reading is handled. While intensive reading is done under the supervision of a teacher, extensive reading is a pleasure activity done by the learners on their own. Since it is an individual assignment, many studies were done about it to see the exact nature and contribution of it to learning and to try to find ways to urge the learners to do this kind of activity. Thus, there is a great deal of accumulated research on it.

\subsection{Reading}

Reading, in very basic terms, can be defined as recognizing the words, including their spelling, and their relations to other words in a sentence. In other words, it is a process of extracting and constructing meaning through a given material in written form (Aukerman, 2013). Gaining the ability to read in a second language is a demanding process and that ability can be seen as the most durable second language learning skill to acquire (Bernhardt, 1993).

Two different dimensions of reading could be handled:

1) Interpersonal dimension

2) Intrapersonal dimension

Interpersonal dimension denotes social side of reading through which students gain different perspectives about what they read and develop a certain kind of criticism or manner towards the reading material. As a result, the readers construct their own subjective view in relation to their beliefs, cultural background and social life, and an individual acquires a different point of view making him peculiar. As for the second one, the reader gains a special conceptualization of the words in the text and develops a meaningful chain in the material they read (Bernhardt, 2011).

Reading in second language learning context is described to have a central role through learning process of the target language, and by nature, it is classified into two forms in related literature:
1) Intensive reading
2) Extensive reading

\subsection{Intensive Reading}

In general terms, intensive reading is about progressing in the given language through reading under teacher's 
guidance. The teacher provides the students with unknown vocabulary and difficult sentence structures, so the learning mostly occurs in lexical and syntactic level (Richards \& Schmidt, 2012). It is intended in intensive reading to procure detailed meaning by dealing with different aspects so that the reader takes the opportunity of making use of various reading abilities such as identifying the main idea, extracting the minor ideas, scanning for specific information, paying close attention to specified vocabulary and grammar. Moreover, it could also deal with translation (Carrell \& Carson, 1997).

\subsection{Extensive Reading}

\subsubsection{Definition}

When extensive reading is at issue, one of the first definitions given is reading large quantities of specially designed materials rapidly for general comprehension with special focus on meaning in the target language (Bambord \& Richard, 2004). The given material in extensive reading is to provide the opportunity for the students to fairly understand it without any assistance from an outer source (Aliponga, 2013).

In a Second Language Learning environment, students should be exposed to large quantities of target language input, which is succeeded through extensive reading the most(Aliponga, 2013). Furthermore, readers take the opportunity to read at their own pace and in their own time limits. By this way, students adapt their reading speed and gain the ability to read faster in their further readings (Tanaka \& Stapleton, 2007).

\subsubsection{Historical Background}

The historical background of the research about extensive reading is likely to give more clear mental picture about it. Michael West, while he was preparing extra reading materials, determined the aim of this kind of reading in a way so as to make use of the facility to utilize the vocabulary that was already learnt in a given reading text, which gives the reader the feeling of accomplishment and pleasure (West, 1955). Later on, it was described as reading a quantity of materials in target language over a certain time period (Bright \& McGregor, 1977). Davis (1995) describes extensive reading as "pupils are given the time, encouragement and materials to read pleasurably, at their own level, as many books as they can, without the pressures of testing or marks" (p. 329 ).

The term "extensive reading" was originated by Palmer in 1917 in order to differentiate it from intensive reading. This term was defined as reading longer passages just for pleasure in simplified language forms and the purpose was determined as comprehending the general meaning and being able to pursue it to the end without the intention of focusing on grammatical and lexical components (Chiu-Kuei, 2015).

Walter (2003) point out to another dimension by stating that the learners choose the text to read themselves freely and they do not mind reading that material (Walter, 2003). In other words, the readers choose the material according to their taste and they deal with it eagerly. In order to achieve the goal of having the students read the materials, they should be given the facility of reaching them and be loaded with enthusiasm and motivation, even more, they should be given enough time to do such an activity (Walter, 2003).

\subsubsection{Theoretical Framework}

Another point that is to be highlighted is that extensive reading directly corresponds to Krahsen's "Input Hypothesis". He formulates his hypothesis as $\mathrm{i}+1$ and points out that if the learners are given sensible amount of input regularly, they will acquire that language most efficiently. " $i$ " denotes to the knowledge about the target language and "+ 1" is the extra input given to the learners. They process the extra information they are exposed to by trying to close the gap between what they already know and they are given first time. In this way, they build up their knowledge by processing and gain more to attain next step (Krashen, 1985). Furthermore, he continues to assert that if the comprehensible input is given in enough amount, the grammar will be comprehended automatically. In this way, the teacher does not need to give the next grammar structure in the planned order because the learners will automatically acquire the structures. He also adds that it will come true on condition that the student is exposed to comprehensible input (Krashen, 1985).

In fact, Krashen comes up with five different hypotheses about second language acquisition. It can be asserted that the "Input Hypothesis" seems the most relevant one to extensive reading, but the others also serve some functions during extensive reading. The other four are as follows: (Krashen, 1985).

1) The Acquisition-Learning Theory: It differentiates between acquiring a language and learning a language. It states that acquisition is a subconscious process that children go through while they are living in the natural environment of their native language. On the other hand, learning is about the second language and it is a conscious process. 
2) Natural Order Hypothesis: People learn the rules of a language in a natural order and some rules come earlier than the others.

3) Monitor Hypothesis: It is about how learning and acquisition are utilized in production processes. Human acquired knowledge accounts for producing utterances in target language. This kind of knowledge is subconscious. Learning is a conscious process and it serves as Monitor and we use learning to make corrections and change what we produce during speaking and writing. At this point, in order for the Monitor to serve correctly, the learner must meet two conditions: i) They must develop a sense for correctness and ii) they must know the rule.

4) Input Hypothesis: It is explained above.

5) Affective Filter Hypothesis: While a learner should be exposed to comprehensible input for acquisition, it is not sufficient on its own. The learners should be open to new input. Learners sometimes develop an "affective filter" or what it is named as "mental block" which prevents them from effectively processing the comprehensible input. When the learner is anxious or lacks in self-confidence, this filter does not allow the learner to get the most of learning process, even it lowers it to undesired degrees in which the learners attain much less than expected.

These hypotheses have something to do with extensive reading. Although second language learning is strongly related to conscious processes, it is not always that kind. As the Input Hypothesis implies, learners go through some unconscious processes, which is achieved effectively in extensive reading. As for Natural Order Hypothesis, since the materials are intentionally prepared for second language learners, the rules are given in that natural order. It can also be asserted that extensive reading lowers the effects of anxiety and the learners become more self-confident as they read comprehensible material and take pleasure. This process makes the affective filter less effective and the learners get the most of it (Chang, 2015).

Extensive reading has also a certain kind of relationship with "Bootstrap Hypothesis". Bamford (1997) borrowed this hypothesis from engineering and applied it to Second Language Learning literature. It is described as "a process in which the results of an action are fed back to achieve greater results more quickly with less effort" (Bamford \& Day, 1997, p. 30). If the initial experiences of the learners with extensive reading are positive, then they will be more confident and produce much better results during reading and learning. Later on, with the experiences of accomplishment, they will feel more urged to reading, and as a result, their overall achievement in language learning will be boosted.

Another theory which urges extensive reading describes a condition in which when learners find the material interesting enough, they read it more attentively. This process leads them to indulge into the natural development of the meaning and they start to use their background knowledge to extract the meaning by using the phrases and ideas in the material instead of decoding the meaning through the words and grammatical structures (Waring, 1997).

\subsubsection{Teachers' Roles}

Extensive reading is by nature defined as the students' self-activity, but the roles of the teachers as supervisors are of the great importance. Although extensive reading is seen to have a central role in language learning and students show great effort at the beginning, their enthusiasm subsides and wanes in further steps. It should also be noted that a true extensive reading requires reading a lot of material and being exposed to that target language in that way. If one loses his enthusiasm in time, reading extensively will not serve in a desired way. Moreover, there is the danger of the learners' ending up with frustration when they have the feeling that there is too much to read. In all these circumstances, the teachers have important roles to refresh the students and re-motivate them to read. In other words, the teachers are assigned the role of nurturing the students (Komiyama, 2013).

Grabe (2009) comes up with another dimension of teachers' roles to motivate students. He believes that for extensive reading to be reasonably successful, the teachers should motivate the students for more effort. He goes further and states that promoting motivation to read requires creating opportunities for students i) achieving consistently, ii) providing student autonomy and iii) students' collaboration (Grabe, 2009). The first two are achieved in extensive reading programs by facilitating the opportunity to reach the materials and having students choose their own reading material. These two are commonly applied in learning environments, but the third one that implies students' working together on the reading material is not intended and is seen against the nature of extensive reading. But Kirchhof (2015) reached different findings in her research. She created a discussion environment among her students to share their ideas about a book that was given to them to read extensively. As the students talked about some interesting points of the reading material, the others seemed to be more interested 
and motivated to read that material. So she found out that 38 of 41 students expressed positive opinions about book talk and they admitted that the talk urged them to read. As a result, she concluded that student colloboration through book talk increases the students' motivation to read extensively (Kirchhoff, 2015).

\subsubsection{Characteristics of an Extensive Reading Program}

Before encouraging the students to read extensively, one should keep the following principles in mind:

1) The amount of the material to read and the time given to the students must be appropriate. It is the teacher's duty to take into account if the curriculum and the load to students to read match. If the students are overloaded with other courses, they will most probably not meet the requirements to read a certain amount.

2) Reading speed is directly related to the students' proficiency level. It is clear that beginner levels cannot read as quickly as other levels, so the teacher should take this point into account and load the students with reading task properly.

3) The teacher can give definite targets to the students. It could be number of pages to be read throughout a certain time period.

4) Evaluation is an important element and the teacher can achieve this in two ways: i) individual assessment with their progress, ii) checking their pre-determined targets in an evaluation form.

5) Monitoring the students' progress is an important task for the teachers. They can achieve this target in several ways: a) A reading notebook: Students can fill in forms daily summarizing what they read and what activities they did there in detail. b) A weekly reading diary: If the previous option is time-consuming and not realistic for some special reasons in the institution, the students can fill in the forms weekly and in less detailed form. c) Book reports: The students can summarize the book and express their opinion of the book when they finish it. d) Negotiated Evaluation: The teacher can negotiate with the students about how they will be graded.

6) After choosing the right books for the students, they are given the opportunity to read outside the school environment, which promotes their autonomy.

7) Their proficiency level is important while determining the right level of the books. There are also ideas that if the reading material is just below their levels, they will feel more confident at the beginning. As their levels get higher, it is better to load them with more difficult material. The underlying idea is that they will be promoted to read easier materials.

8) The use of dictionary is not appropriate and the teachers should prevent them from using because it will slow them down and it may cause to get bored and frustrated as they refer to the dictionaries (Day\&Bamford, 1998).

Another point that sees extensive reading distinctive in certain characteristics comes up with following suggestions:

1) Students are exposed to a great amount of reading materials.

2) Students are generally free to choose what they want to read.

3) The materials are different from each other in terms of content and genre.

4) The materials are correspondent to their proficiency level.

5) Post-reading activities are generally applied for evaluation.

6) Teachers also read the materials for modeling and checking the comprehension. the teachers keep up with the students' progress (Renandya \& Jacobs, 2002).

\subsubsection{Advantages of Extensive Reading}

Different researchers generally agree on the certain advantages of reading extensively. They especially point out that it is a very useful source for developing proficiency in target language. Hedgcock \& Ferris put forth the following advantages:

1) It improves comprehension skills.

2) It helps to develop automaticity and thus students' production gets better.

3) It contributes to background knowledge.

4) It helps to build up linguistic knowledge.

5) It promotes Students' confidence and motivation and makes the learning process quicker and easier (Hedgcock \& Ferris, 2009). 
Day \& Bramford (1998) add more points to these mentioned above. They state that students develop reading habits by this way and they get prepared for further reading. Moreover, it helps them develop some academic skills (Day \& Bamford, 1998)

Al-Homoud \& Schmitt (2009) concluded that extensive reading has some valuable consequences. Firstly, it improves reading comprehension. Reading a text quickly and comprehending it without extra effort requires an important background and the students who read the given material seemed to understand much more easily. It also helps improve reading speed. As the students deal with the material, they develop their skills to read with a better speed. Moreover, it facilitates enriching vocabulary knowledge. As the students see the words in meaningful context, they learn much easier than when they see the single words exempt from any context. Furthermore, the students develop positive attitudes towards second language learning. It is also reported there are certainly some situations in which students did not develop positive attitudes towards reading under some circumstances. But in general, it is agreed upon that reading extensively provides improvement in attitudes towards further reading (Al-Homoud \& Schmitt, 2009).

\section{Method}

\subsection{The Purpose of the Study}

The purpose of this research is to check the effectiveness of extensive reading on elementary adult learners of English as far as the following headings are concerned:
1) Collocations
2) Prepositions used after verbs and adjectives
3) Words that can be confused easily
4) Second meaning of a word
5) Sentence structure and inversion
6) Pronunciation

\subsection{Participants}

All of the participants are adult learners of English at elementary and pre-intermediate levels and they are 12 people in total. All of them had a certain background of English during school years but they say they forgot most of their English and they started to learn it again during their career. They are especially chosen because some structures are fossilized in their minds and they are more exposed to first language interference.

\subsection{Materials}

The source for reading is a graded reading book named as "The Coldest Place on Earth" (Vicary, 2008). As the back cover reveals it, it is a true story about an expedition to the South Pole. It is a story about two explorers racing to reach the South Pole point first. This is a stage 1 story with 400 hundred headwords just over starter level.

Secondly, a test about vocabulary, sentence structure and pronunciation was prepared from this story. This test was applied to 12 participants.

\subsection{Limits of this Study}

First of all, they were all male learners of English, so the inclinations of female learners were not tested in this study. Secondly, although they were adult learners, their age range is quite wide, for instance, the youngest of the participants is 24 years old and the eldest one is 43 . Although they had almost the same background of English during their school years, they had different experiences with English during their careers. While some of them have just finished university and their knowledge is clear in their minds, some of others have not dealt with English for long. There is still another group which was exposed to English in a very limited way during their careers. All of these different groups could have handled differently. Another point is that all of the participants were from Turkish citiens and they attended schools in Turkey, so we do not have a chance to evaluate other nations because their educational systems may have given them different opportunities and background. The last point that should be underlined is that people normally do the extensive reading in an unconscious way, but here in the study, the participants firstly dealt with the questions and then they read the story, and as a matter of fact, they paid special attention to the points in the story which they already saw in the test.

\subsection{Procedure}

The 12 participants were selected from elementary to pre-intermediate level and they were told that they would 
be given a story book to read, but before that, a test about vocabulary, sentence structure and pronunciation would be administered to them.

The questions were classified under the headings mentioned above. All of the questions were taken directly from the storybook and the participants firstly had the test (see Appendix). Then the participants were taken one-by-one to pronounce the given words from the text. The correct and wrong pronunciation were noted down. After they finished the test, they were asked to read the storybook with special attention to the parts they were examined.

\section{Results}

The distribution of the questions in the test according to the titles mentioned above is as follows:

\begin{tabular}{ll}
\hline Question Type & Question Number \\
\hline Collocations & $1-2$ \\
Prepositions used after verbs and adjectives & $3-4$ \\
Words that can be confused easily & $5-6-7$ \\
Second meaning of a word & 8 \\
Sentence structure and inversion & 9 \\
Pronunciation & 10 \\
\hline
\end{tabular}

The first 8 questions and the participants' answers are as follows: ("T" stands for "true", "F" stands for "false", "PT" stands for partially true.)

\begin{tabular}{lllllllll}
\hline Participants & Q1 & Q2 & Q3 & Q4 & Q5 & Q6 & Q7 & Q8 \\
\hline Participant 1 & T & T & T & F & T & F & T & T \\
Participant 2 & T & T & F & T & F & F & T & T \\
Participant 3 & T & F & F & F & F & F & T & PT \\
Participant 4 & T & T & F & F & F & F & F & T \\
Participant 5 & F & T & F & F & F & F & F & T \\
Participant 6 & F & F & F & F & F & F & F & PT \\
Participant 7 & T & T & T & F & F & F & T & T \\
Participant 8 & F & T & F & T & F & F & T & T \\
Participant 9 & T & F & F & F & T & F & F & PT \\
Participant 10 & T & T & T & T & T & F & F & T \\
Participant 11 & T & T & T & T & T & F & F & T \\
Participant 12 & F & T & F & F & F & F & F & PT \\
\hline
\end{tabular}

The question types and the distribution of the wrong answers are as follows:

\begin{tabular}{|c|c|c|c|c|c|c|}
\hline Question Type & \multicolumn{2}{|c|}{ Question Number } & \multicolumn{2}{|c|}{ Number Of Wrong Answers } & \multicolumn{2}{|c|}{ Percentage } \\
\hline \multirow{2}{*}{ Collocations } & \multicolumn{2}{|c|}{1} & \multicolumn{2}{|c|}{4} & \multicolumn{2}{|c|}{$33 \%$} \\
\hline & \multicolumn{2}{|c|}{2} & \multicolumn{2}{|l|}{3} & \multicolumn{2}{|c|}{$25 \%$} \\
\hline Question Type & & \multicolumn{2}{|c|}{ Question Number } & \multicolumn{2}{|c|}{ Number Of Wrong Answers } & Percentage \\
\hline \multirow{2}{*}{\multicolumn{2}{|c|}{$\begin{array}{l}\text { Prepositions used after verbs and } \\
\text { adjectives }\end{array}$}} & \multirow{2}{*}{\multicolumn{2}{|c|}{$\begin{array}{l}3 \\
4 \\
\end{array}$}} & 8 & & $66 \%$ \\
\hline & & & & 8 & & $66 \%$ \\
\hline \multicolumn{2}{|l|}{ Question Type } & \multicolumn{2}{|c|}{ Question Number } & Number Of Wrong Answers & \multicolumn{2}{|c|}{ Percentage } \\
\hline \multirow{3}{*}{\multicolumn{2}{|c|}{ Words that can be confused easily }} & 5 & \multicolumn{2}{|r|}{8} & \multicolumn{2}{|c|}{$66 \%$} \\
\hline & & 6 & \multicolumn{2}{|c|}{12} & \multicolumn{2}{|c|}{$100 \%$} \\
\hline & & 7 & \multicolumn{2}{|c|}{7} & \multicolumn{2}{|c|}{$58 \%$} \\
\hline Question Type & \multicolumn{2}{|c|}{ Question Numbe } & \multicolumn{2}{|c|}{ Number Of Wrong Answers } & \multicolumn{2}{|c|}{ Percentage } \\
\hline Second meaning of a word & \multicolumn{2}{|c|}{8} & \multicolumn{2}{|c|}{4} & \multicolumn{2}{|c|}{$33 \%$} \\
\hline
\end{tabular}


The first two questions are about collocations: "win a race" and "make mistake". Only 4 and 3 out of 12 participants made mistakes here. It seems they are generally conscious of this type. But as for the question 3 and $4,66 \%$ of the participants did them wrongly because the wrong answers are true in their first language. Instead of "left Cape Evans" and "angry with Johansen", word-by-word translation from their mother tongue is "left from Cape Evans" and "angry to Johansen". As a result, there is a problem of first language interference.

The question number 5 measures if the participants know the difference between "get angry" and "be angry" and it seems $66 \%$ of them are not aware of this difference yet.

In question 6, none of the participants answered correctly because they overgeneralized the rule to the situation and attached a meaning using their intuition. They thought "nearly" has something to do with "near".

Question number 7 is another tricky one for them because they know that the suffix "-er" makes a verb into "doer of the action", so they again overgeneralized and thought that "a cook" cannot be a person although there are some other participants who exactly know the meaning of that word.

In question number 8 , they were tested if they knew the second meaning of the verb "call" and it was found out that $33 \%$ of them did not know its second meaning.

With question number 9, it was intended to measure their knowledge of sentence structure. There are 4 sentences from the story which were assumed to have unfamiliar sentence structure for them. The first three sentences were used in a way that the adverbs were just at the beginning of the sentences and the fourth one has totally unfamiliar structure. They were asked to rewrite the sentences in correct way. The results are as follows:

\begin{tabular}{lll}
\hline The Sentence From The Story & Number of Students Who Made Corrections & Percentage \\
\hline ....then, slowly, the sledge moved again. & 3 & $25 \%$ \\
Slowly, they walked on. & 3 & $25 \%$ \\
Under the map, Scott wrote the day for the start of their journey. & 3 & $25 \%$ \\
Behind him was a big map. & 12 & $100 \%$ \\
\hline
\end{tabular}

For the first three sentences, 9 participants did not make any change and they thought there is no need to change these sentences into any form, but three of them made changes and they wrote the adverbs at the end of the sentences, for example they corrected the first one as follows: “....then the sledge moved again slowly." In fact, they made the same change for the other two sentences. It should also be noted that the same three participants made the same changes and the other 9 did not change anything.

As for the last sentence, all of the students thought that it is a wrong sentence and they tried to correct this sentence two different ways:

1) A big map was behind him.

2) There was a big map behind him.

In the last question, the participants were asked to pronounce the words from the story. The words are as follows:

\begin{tabular}{|c|c|c|c|c|}
\hline Words & Correct Pronunciation & $\begin{array}{l}\text { Number Of Participants Who } \\
\text { Mispronounced }\end{array}$ & Percentage & Participants' Pronunciation \\
\hline Excited & /Ik'sar.tid/ & 12 & $100 \%$ & /eg'zai.tid/ \\
\hline Captain & /'kæp.tın/ & 5 & $41 \%$ & /'kæp.tein/ \\
\hline Laugh & /la:f/ & 7 & $58 \%$ & /lavg/ \\
\hline Island & /'ar.lənd/ & 9 & $75 \%$ & /'ars.lənd/ \\
\hline Ski & /ski:/ & 10 & $83 \%$ & /ska1/ \\
\hline Sledge & /sledz/ & 0 & 0 & /sledz/ \\
\hline Arrive & /o'raiv/ & 5 & $41 \%$ & /o'rr:v/ \\
\hline journey & /'d33:.ni// & 5 & $41 \%$ & /'dzu:.nei/ \\
\hline
\end{tabular}

The last column shows the participants' mispronunciation. It should be highlighted that they mispronounced the words in the same way. In other words, they did not offer any other form of mispronunciation than the given ones above.

Later on, after the test, the participants were firstly introduced to the storybook and they were told to read it. After they completed reading the book, they were again given the same test. They were given their previous 
papers and asked to make necessary changes if they think there should be. The new results are as follows:

\begin{tabular}{lllllllll}
\hline Participants & Q1 & Q2 & Q3 & Q4 & Q5 & Q6 & Q7 & Q8 \\
\hline Participant 1 & $\mathrm{T}$ & $\mathrm{T}$ & $\mathrm{T}$ & $\mathrm{T}$ & $\mathrm{T}$ & $\mathrm{T}^{*}$ & $\mathrm{~T}$ & $\mathrm{~T}$ \\
Participant 2 & $\mathrm{T}$ & $\mathrm{T}$ & $\mathrm{T}$ & $\mathrm{T}$ & $\mathrm{F}$ & $\mathrm{T}^{*}$ & $\mathrm{~T}$ & $\mathrm{~T}$ \\
Participant 3 & $\mathrm{T}$ & $\mathrm{T}$ & $\mathrm{T}^{*}$ & $\mathrm{~T}^{*}$ & $\mathrm{~F}$ & $\mathrm{~F}$ & $\mathrm{~T}$ & $\mathrm{~T}^{*}$ \\
Participant 4 & $\mathrm{T}$ & $\mathrm{T}$ & $\mathrm{F}$ & $\mathrm{T}^{*}$ & $\mathrm{~F}$ & $\mathrm{~F}$ & $\mathrm{~T}^{*}$ & $\mathrm{~T}$ \\
Participant 5 & $\mathrm{T}$ & $\mathrm{T}$ & $\mathrm{F}$ & $\mathrm{F}$ & $\mathrm{F}$ & $\mathrm{F}$ & $\mathrm{F}$ & $\mathrm{T}$ \\
Participant 6 & $\mathrm{F}$ & $\mathrm{F}$ & $\mathrm{T}$ & $\mathrm{F}$ & $\mathrm{F}$ & $\mathrm{F}$ & $\mathrm{F}$ & $\mathrm{PT}$ \\
Participant 7 & $\mathrm{T}$ & $\mathrm{T}$ & $\mathrm{T}$ & $\mathrm{T}$ & $\mathrm{F}$ & $\mathrm{F}$ & $\mathrm{T}$ & $\mathrm{T}$ \\
Participant 8 & $\mathrm{T}$ & $\mathrm{T}$ & $\mathrm{F}$ & $\mathrm{T}$ & $\mathrm{F}$ & $\mathrm{F}$ & $\mathrm{T}$ & $\mathrm{T}$ \\
Participant 9 & $\mathrm{T}$ & $\mathrm{F}$ & $\mathrm{T}$ & $\mathrm{F}$ & $\mathrm{T}$ & $\mathrm{F}$ & $\mathrm{F}$ & $\mathrm{T}$ \\
Participant 10 & $\mathrm{T}$ & $\mathrm{T}$ & $\mathrm{T}$ & $\mathrm{T}$ & $\mathrm{T}$ & $\mathrm{T}$ & $\mathrm{T} *$ & $\mathrm{~T}$ \\
Participant 11 & $\mathrm{T}$ & $\mathrm{T}$ & $\mathrm{T}$ & $\mathrm{T}$ & $\mathrm{T}$ & $\mathrm{F}$ & $\mathrm{F}$ & $\mathrm{T}$ \\
Participant 12 & $\mathrm{F}$ & $\mathrm{T}$ & $\mathrm{F}$ & $\mathrm{T}$ & $\mathrm{F}$ & $\mathrm{F}$ & $\mathrm{F}$ & $\mathrm{PT}$ \\
\hline
\end{tabular}

Note. *Astericks show the answers that the participants corrected after reading the story.

The new distribution is as follows:

\begin{tabular}{lllll}
\hline Question Type & Question Number & Number Of Wrong Answers & Percentage & Previous Percentage \\
\hline Collocations & 1 & 2 & $16 \%$ & $33 \%$ \\
& 2 & 2 & $16 \%$ & $25 \%$ \\
\hline
\end{tabular}

It seems there is slight change in their true answers and the reading helped 2 participants out of 4 to correct their answer in question 1 and 1 of 3 wrongdoers corrected himself in the question 2.

\begin{tabular}{lllll}
\hline Question Type & Question Number & Number Of Wrong Answers & Percentage & Previous Percentage \\
\hline Prepositions used after & 3 & 4 & $33 \%$ & $66 \%$ \\
verbs and adjectives & 4 & 3 & $24 \%$ & $66 \%$ \\
\hline
\end{tabular}

Half of the wrongdoers learned that "leave a place" is the correct use and they realized that "leave from a place" is not true in English. The two participants who corrected their mistakes expressed that they previously knew that point wrongly because it was true in their mother tongue and they corrected themselves after reading this story.

\begin{tabular}{lllll}
\hline Question Type & Question Number & Number Of Wrong Answers & Percentage & Previous Percentage \\
\hline Words that can be & 5 & 8 & $66 \%$ & $66 \%$ \\
confused easily & 6 & 9 & $75 \%$ & $100 \%$ \\
& 7 & 5 & $41 \%$ & $58 \%$ \\
\hline
\end{tabular}

None of the wrongdoers noticed the difference between "get angry" and "be angry" because they said that they did not see any clue in the text to make them realize the difference. In question 6 , the participants were asked to come up with the exact meaning of "nearly" and none of them answered it correctly. They said that they just used their previous knowledge about adverbs and they thought that the suffix "-ly" makes an adjective into an adverb and the meaning does not change, and 3 of the participants realized in the text that "nearly" has a different meaning and they said they remembered the other option in the test and when they substituted the words, the sentence seemed correct. There is the same problem in question 7. Previously, 7 of 12 participants answered this question wrongly, but after reading, only 2 of the wrongdoers corrected themselves. The others said that they did not notice any difference in the text.

\begin{tabular}{lllll}
\hline Question Type & Question Number & Number of Wrong Answers & Percentage & Previous Percentage \\
\hline Second meaning of a word & 8 & 2 & $16 \%$ & $33 \%$ \\
\hline
\end{tabular}


In question 8, 4 of 12 participants did not know the second meaning of the verb "call". After reading, 2 of them corrected themselves and they said they remembered the pictures in the test and realized that the verb "call" does not only mean "phone somebody" and it gives better meaning in the text when they put the other meaning there. The other 2 participants did not notice anything.

The total success at the first test was $43.75 \%$ and it changed into $63.55 \%$. It is almost $20 \%$ increase in their total success. Another point that should be pinpointed is that the more successful participants in the first test corrected themselves more than the weak ones, so it could be concluded that the more successful ones were more attentive during reading.

In question 9, all of the students realized that this kind of sentence structure is possible in English. The 3 participants who changed the places of adverbs said that they became more conscious about sentence structure and it was a good experience for them to read this story.

As for the last sentence "Behind him was a big map", all of the students expressed their doubt about it and they made changes to this sentence. Since this sentence became the center of attention among them, they especially noticed this sentence in the story and saw that it is a true sentence and later, none of them made any change to it.

As for pronunciation, it is obvious that an extensive reading passage has nothing to do with it. After reading the story, the participants were given the correct pronunciation of these words and they corrected themselves. But still, they could not correct the pronunciation of the word "excited" because they said they learned it in the way that they mispronounced. Even more, they felt extremely puzzled when they learned that they had been mispronouncing this word for years because all of the participants know this word and none of them knows the correct pronunciation. After several attempts in different days, they were still mispronouncing this word. They said that they learned this word as they pronounced and they had been using in this way, so it is very difficult to change it all of a sudden. We concluded that some words become even more fossilized when they are repeated during extensive reading.

As for the word "ski", those who mispronounced said they were exposed to correct pronunciation, but intuitively they are inclined to pronounce it in the wrong way. After some trials, they said they would not forget the right pronunciation again. Another point that draws attention here is that none of the students knew the meaning of the word "sledge" and all of them pronounced it correctly. We can conclude that they developed a certain way of intuition towards pronunciation of English words and some of these words directly correspond to their intuition and they are pronounced correctly while many other words do not match their guesses.

\section{Conclusion}

The results show that extensive reading has important impact on language learning. The readers become aware of the collocations which are the natural use of word combinations. Moreover, they become conscious of other meanings of words and different types of sentence construction. Furthermore, they acquire an ability to be flexible and not to overgeneralize every rule because the extensive reading materials give them the opportunity to see many points out of the rule that they previously learned. The readers in this study became aware that the uses of prepositions do not match their first language so they had to learn them as they are in the target language. The fact that the participants did not realize the difference between "get angry" and "be angry" shows that there are certain points that do not develop at this point. Like many other studies, this study also indicated that first language interference play an important role on their learning. The last point to be underlined is that extensive reading makes mispronunciation even more fossilized.

\section{References}

Al-Homoud, F., \& Schmitt, N. (2009). Extensive reading in a challenging environment: a comparison of extensive and intensive reading approaches in Saudi Arabia. Language Teaching Research, 13(4), 383-401. https://doi.org/ 10.1177/1362168809341508

Aliponga, J. (2013). Reading Journal: Its Benefits for Extensive Reading. International Journal of Humanities and Social Science, 3(12), 73-80.

Aukerman, M. (2013). Rereading comprehension pedagogies: Toward a dialogic teaching ethic that honors student sensemaking. Dialogic Pedagogy, 1, 1-31. https://doi.org/ 10.5195/dpj.2013.9

Bambord, J., \& Richard, D. (2004). Extensive Reading Activities for Teaching Language. Cambridge: Cambridge University Press

Bamford, J., \& Day R. R., (1997). Extensive reading: What is it? Why bother?. The Japan Association for Language Teaching, 21(5), 6-8. 
Bernhardt, E. B. (1993). Reading Development in A Second Language: Theoretical, Empirical, \& Classroom Perspectives. London: Ablex Publishing Corporation.

Bernhardt, E. B. (2011). Understanding Advanced Second-Language Reading. New York: Routledge Taylor and Francis Group.

Bright, J. A., \& McGregor, G. P. (1977). Teaching English as a Second Language. London: Cambridge University Press

Carrell, P. L., \& Carson, J. G. (1997). Extensive and intensive reading in an EAP setting. English for Specific Purposes, 16, 47-60. https://doi.org/10.1016/S0889-4906(96)00031-2

Chiu-Kuei C. C. (2015). Applying Extensive Reading to Improve Unmotivated Learners' Attitudes toward Reading in English. International Journal of Learning, Teaching and Educational Research, 13(2), 1-25.

Davis, C. (1995). Extensive reading: an expensive extravagance? ELT Journal, 49, 329-335. https://doi.org/10.1093/elt/49.4.329

Day, R., \& Bamford, J. (1998). Extensive Reading in the Second Language Classroom. UK: Cambridge University Press.

Grabe, W. (2009). Reading in A Second Language: Moving from Theory to Practice. New York, NY: Cambridge University Press.

Hedgcock, J. S., \& Ferris, D. R. (2009). Teaching Readers of English: Students, Texts, and Contexts. New York: Routledge.

Kirchhoff, C. (2015). Extensive Reading in the EFL Classroom: Benefits of a Face-to-Face Collaboration Activity. Reading Matrix: An International Online Journal, 15(1), 54-65.

Komiyama, R. (2013). Factors underlying second language reading motivation of adult EAP students. Reading in a Foreign Language, 25(2), 149-169.

Krashen, S. D. (1985). The Input Hypothesis: Issues and Implications. New York: Longman

Michael, W. (1955). Simplified and Abridged. In W. R. Lee (Ed., 1967), ELT Selection. London: Oxford University Press.

Renandya, W. A., \& Jacobs, G. M. (2002). Extensive reading: Why aren't we all doing it? In J. C. Richards \& G. C. Jacobs (Eds.), Methodology in Language Teaching: An Anthology of Current Practice. Cambridge: Cambridge University Press. https://doi.org/10.1017/CBO9780511667190.041

Richards, J. C., \& Schmidt, R. (2002). Longman Dictionary of Language Teaching and Applied Linguistics. Malaysia: Pearson Education.

Tanaka, H., \& Stapleton, P. (2007). Increasing reading input in Japanese high school EFL classrooms: An empirical study exploring the efficacy of extensive reading. The Reading Matrix, 7(1), 115-131.

Vicary, T. (2008). The Coldest Place on Earth. Oxford: Oxford University Press.

Walter, H. C. (2003). Reading in a second language. Retrieved from http://www.llas.ac.uk/resources/gpg/1420

Waring, R. (1997). Graded and extensive reading-questions and answers. The Language Teacher, 21(5), 9-12.

\section{Appendix}

Name:

Surname:

Answer the following questions.

1-) win

a-) the race b-) the other team

2-) Which one is true?

a-) do mistake b-) make mistake

3-) Which one is true?

a-) They left Cape Evans. 
b-) They left from Cape Evans.

4-) He was angry Johansen.

a-) with b-) to

5-) Is there any difference between these two sentences?

"He got angry."

"He was angry."
a-) Yes
b-) no
c-) not sure
6-) nearly
a-) almost
b-) next to

7-) What is " $\underline{a \text { cook" }}$ "?
a-) a person
b-) a machine

8-) Which picture means "call"?

a-)

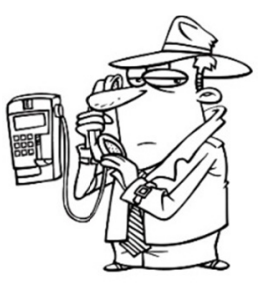

b-)

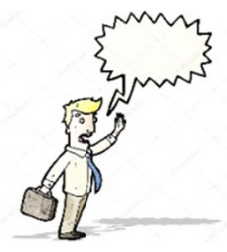

9-) Correct these sentences if they are not true.

a-) ....then, slowly, the sledge moved again.

b-) Slowly, they walked on.

c-) Under the map, Scott wrote the day for the start of their journey.

d-) Behind him was a big map.

\section{0-) Read these words aloud.}

\section{Words to pronounce:}

Excited

Captain

Laugh

Island

Ski

Sledge

Arrive

Journey 


\section{Copyrights}

Copyright for this article is retained by the author(s), with first publication rights granted to the journal.

This is an open-access article distributed under the terms and conditions of the Creative Commons Attribution license (http://creativecommons.org/licenses/by/4.0/). 